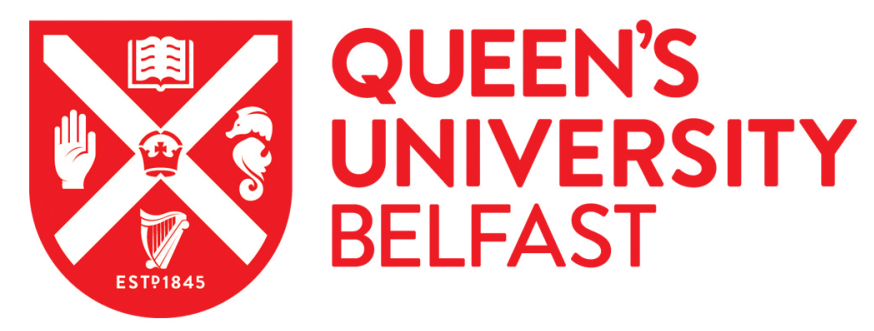

\title{
Effects of modified lipoproteins on human trophoblast cells: a role in pre-eclampsia in pregnancies complicated by diabetes
}

\author{
McLeese, R. H., Zhao, J., Fu, D., Yu, J. Y., Brazil, D. P., \& Lyons, T. J. (2021). Effects of modified lipoproteins \\ on human trophoblast cells: a role in pre-eclampsia in pregnancies complicated by diabetes. BMJ open diabetes \\ research \& care, 9, [e001696]. https://doi.org/10.1136/bmjdrc-2020-001696
}

Published in:

BMJ open diabetes research \& care

Document Version:

Publisher's PDF, also known as Version of record

Queen's University Belfast - Research Portal:

Link to publication record in Queen's University Belfast Research Portal

\section{Publisher rights}

Copyright 2021 the authors.

This is an open access article published under a Creative Commons Attribution License (https://creativecommons.org/licenses/by/4.0/), which permits unrestricted use, distribution and reproduction in any medium, provided the author and source are cited

\section{General rights}

Copyright for the publications made accessible via the Queen's University Belfast Research Portal is retained by the author(s) and / or other copyright owners and it is a condition of accessing these publications that users recognise and abide by the legal requirements associated with these rights.

Take down policy

The Research Portal is Queen's institutional repository that provides access to Queen's research output. Every effort has been made to ensure that content in the Research Portal does not infringe any person's rights, or applicable UK laws. If you discover content in the Research Portal that you believe breaches copyright or violates any law, please contact openaccess@qub.ac.uk. 
BMJ Open

Diabetes

Research

\& Care

\title{
Effects of modified lipoproteins on human trophoblast cells: a role in pre- eclampsia in pregnancies complicated by diabetes
}

\author{
Rebecca Helen McLeese (10 , ${ }^{1,2}$ Jiawu Zhao, ${ }^{2}$ Dongxu Fu, ${ }^{2}$ Jeremy $Y \mathrm{Yu},{ }^{1,2}$ \\ Derek P Brazil, ${ }^{2}$ Timothy J Lyons (D) ${ }^{1,2}$
}

To cite: McLeese RH, Zhao J, Fu D, et al. Effects of modified lipoproteins on human trophoblast cells: a role in pre-eclampsia in pregnancies complicated by diabetes. BMJ Open Diab Res Care 2021;9:e001696. doi:10.1136/ bmjdrc-2020-001696

- Supplemental material is published online only. To view please visit the journal online (http://dx.doi.org/10.1136/ bmjdrc-2020-001696).

Received 17 June 2020 Revised 26 November 2020 Accepted 5 December 2020

Check for updates

C Author(s) (or their employer(s)) 2021. Re-use permitted under CC BY. Published by BMJ.

${ }^{1}$ Division of Endocrinology, Medical University of South Carolina, Charleston, South Carolina, USA

${ }^{2}$ Wellcome-Wolfson Institute For Experimental Medicine School of Medicine, Dentistry and Biomedical Sciences, Queen's University Belfast, Belfast, UK

Correspondence to Dr Timothy J Lyons; lyonstj@musc.edu

\section{ABSTRACT}

Introduction Pre-eclampsia (PE) is increased 4-fold by maternal diabetes. Elevated plasma antiangiogenic factors, soluble fms-like tyrosine kinase (sFLT-1) and soluble endoglin (sENG), precede PE onset. We investigated whether diabetesrelated stresses, modified lipoproteins and elevated glucose enhance trophoblast sFLT-1 and SENG release and/or alter placental barrier function and whether oxidized low-density lipoprotein $(0 x-L D L)$ is in placental tissue.

Research design and methods HTR8/SVneo cells were exposed to 'heavily-oxidized, glycated' LDL (HOG-LDL) versus native LDL (N-LDL) (10-200 $\mathrm{mg}$ protein/L) for 24 hours \pm pretreatment with glucose ( $30 \mathrm{mmol} / \mathrm{L}, 72$ hours). Concentrations of SFLT- 1 and SENG in supernatants (by ELISA) and expressions of SFLT-1-113 and sFLT-1-E15A isoforms, endoglin (ENG) and matrix metalloproteinase-14 (MMP-14; by RT-PCR) were quantified. For barrier studies, JAR cells were cultured in Transwell plates (12-14 days), then exposed to LDL. Transepithelial electrical resistance (TEER) was measured after 6, 12 and 24 hours. In placental sections from women with and without type 1 diabetes, immunostaining of apolipoprotein B100 (ApoB, a marker of LDL), 0x-LDL and lipoxidation product 4-hydroxynonenal was performed.

Results HOG-LDL ( $50 \mathrm{mg} / \mathrm{L})$ increased sFLT-1 (2.7-fold, $p<0.01)$ and SENG (6.4-fold, $p<0.001)$ in supernatants versus N-LDL. HOG-LDL increased expression of $5 F L T-1-113$ (twofold, $\mathrm{p}<0.05), s F L T-1-E 15 A$ (1.9-fold, $\mathrm{p}<0.05), E N G$ (1.6-fold, $p<0.01$ ) and MMP-14 (1.8-fold, $p<0.05)$ versus $\mathrm{N}-\mathrm{LDL}$. High glucose did not by itself alter SFLT-1 or SENG concentrations, but potentiated effects of HOG-LDL on SFLT1 by 1.5 -fold $(\mathrm{p}<0.05)$ and on sENG by 1.8 -fold $(\mathrm{p}<0.01)$. HOG-LDL (200 mg/L) induced trophoblast barrier impairment, decreasing TEER at 6 hours $(p<0.01), 12$ hours $(p<0.01)$ and 24 hours $(p<0.05)$ versus N-LDL. Immunostaining of term placental samples from women both with and without diabetes revealed presence of intravillous modified lipoproteins.

Conclusion These findings may explain, in part, the high risk for PE in women with diabetes. The trophoblast culture model has potential for evaluating novel therapies targeting barrier dysfunction.

\section{INTRODUCTION}

Pre-eclampsia (PE) is a major cause of maternal and neonatal morbidity and

\section{Significance of this study}

What is already known about this subject?

- In pregnancy, maternal diabetes increases risk of pre-eclampsia (PE) fourfold, but mechanisms are not well understood.

- Barrier dysfunction is an early general feature of complications of diabetes, as previously illustrated in diabetic retinopathy: low-density lipoprotein (LDL) permeates the diabetic retina, and once extravasated, oxidation and glycation confer cytotoxicity. An analogous process might occur in the placenta.

\section{What are the new findings?}

- In cultured human trophoblasts, modified LDL diminished cell viability, increased release of soluble fmslike tyrosine kinase (sFLT-1) and soluble endoglin (sENG) and induced barrier dysfunction.

- Effects of modified LDL were amplified by high glucose concentrations, which alone had no effect.

- Intravillous modified LDL is present in human term placentae.

How might these results change the focus of research or clinical practice?

- The trophoblast culture model has potential for evaluating novel therapies targeting barrier dysfunction.

- Inhibition of trophoblast signaling pathways activated by combined effects of modified lipoproteins and elevated glucose may ameliorate risk for PE in women with diabetes.

mortality; it is $\sim 4$-fold more frequent in women with diabetes $(\sim 20 \%$ vs $5 \%) .{ }^{1}$ The pathogenesis of PE is poorly understood, but in the second trimester, elevated maternal plasma concentrations of antiangiogenic factors, soluble fms-like tyrosine kinase (sFLT-1) and soluble endoglin (sENG), are predictive. ${ }^{23}$ In women with type 1 diabetes, elevated sFLT-1 predicts PE as expected, but sENG appears to rise excessively in all women with diabetes, perhaps explaining their susceptibility. ${ }^{4}$ sFLT-1 is formed by alternative splicing ${ }^{5}$; the 
main splice variants are $s F L T-1-I 13$, the originally identified form, and sFLT-1-E15a, the placenta-specific form ${ }^{6}$; both are upregulated prior to PE onset. ${ }^{6} 7$ sENG is a proteolytic cleavage product of transmembrane ENG; the mechanism for its enhanced release in PE is unclear but may be mediated by increased matrix metalloproteinase-14 (MMP-14) expression or activity. ${ }^{89}$

Other factors associated with vascular complications of diabetes, including hyperglycemia and dyslipidemia, may modulate PE. ${ }^{10}{ }^{11}$ In a prospective study of pregnant type 1 diabetic women, we found that plasma low-density lipoprotein (LDL) was elevated early in pregnancy in those with subsequent PE. ${ }^{11}$ It is well established that extravasated oxidized LDL (Ox-LDL) in arterial intima mediates atherosclerosis. Likewise, breakdown of the blood retinal barriers permits analogous extravasation and oxidation of $\mathrm{LDL}^{12}$; we found extensive circumstantial evidence implicating these effects in retinal injury. ${ }^{12-16}$ One key lipoxidation product is 4-hydroxynonenal (4-HNE), which has potential to be a surrogate for Ox-LDL in cell culture work.

From these considerations, we postulate that placental lipoprotein extravasation and modification may operate as both cause and consequence of placental barrier dysfunction, thus promoting PE. Metabolic stresses (high/fluctuating glucose concentrations, free fatty acids, oxidative stress, osmotic stress) may contribute to gradual, progressive barrier breakdown, allowing plasma constituents, including lipoproteins, to invade normally inaccessible tissue compartments. Previous studies suggest placental barrier dysfunction in diabetes. ${ }^{17-19} \mathrm{We}$ hypothesize that exposure of placental trophoblasts to modified LDL and/or high glucose concentrations could compromise the maternal-fetal barrier and modulate development of PE.

The aims of this study were: (1) to investigate sFLT-1 and sENG release and expression from invasive trophoblast cells, which are readily exposed to 'heavily oxidized, glycated LDL' (HOG-LDL) and/or elevated glucose; (2) to study effects of these stresses on barrier function of trophoblast monolayer; and (3) to explore whether extravasated LDL is present in human placentae at term from women with and without diabetes.

\section{RESEARCH DESIGN AND METHODS}

Human lipoprotein preparation

Native LDL (N-LDL) and HOG-LDL were prepared as previously described. ${ }^{12}$ Briefly, plasma was pooled from three or four healthy fasted volunteers who were taking neither antioxidant vitamins nor prescribed medications. $\mathrm{N}-L D L$ was isolated by sequential ultracentrifugation (350 $000 \mathrm{~g}$, density $(\mathrm{d})=1.019-1.063 \mathrm{~g} / \mathrm{mL})$. Glycated $\mathrm{LDL}$ (G-LDL) was prepared by incubation with glucose (50 $\mathrm{mmol} / \mathrm{L}, 72$ hours, $37^{\circ} \mathrm{C}$ ) under antioxidant conditions $(1 \mathrm{mmol} / \mathrm{L}$ diethylenetriamine pentaacetate, $270 \mu \mathrm{mol} / \mathrm{L}$ EDTA). HOG-LDL was prepared by oxidizing G-LDL with $10 \mu \mathrm{M}$ copper chloride $\left(\mathrm{CuCl}_{2}\right)\left(24\right.$ hours, $\left.37^{\circ} \mathrm{C}\right)$, followed by repeated dialysis against EDTA (24 hours, $4^{\circ} \mathrm{C}$ ). LDL protein concentration was measured (Pierce BCA Assay, Thermo Fisher Scientific, Rockford, Illinois, USA). LDL fluorescence (ex $355 \mathrm{~nm} / \mathrm{em} 460 \mathrm{~nm}$ ) and absorbance $(234 \mathrm{~nm})$ were determined, and agarose gel electrophoresis performed (SAS-MX Lipoprotein gel, Helena Biosciences Europe, Gateshead, UK) to confirm modification. Preparations were confirmed as endotoxin negative (Limulus Amebocyte Lysate kit, Lonza, Allendale, New Jersey, USA), and cytotoxicity was determined as absent for N-LDL and present for HOG-LDL (cell counting kit-8 (CCK-8) assay, Dojindo Molecular Technologies, Rockville, Maryland, USA). LDL preparations were stored in dark under nitrogen $\left(4^{\circ} \mathrm{C}\right)$. Preparations were used within 1 month and experiments were repeated using different LDL preparations.

\section{Human trophoblast HTR8/SVneo cell cullture}

The first trimester trophoblast cell line HTR8/SVneo was a gift from Professor Charles H Graham, Queen's University, Ontario, Canada. Cells were seeded into sixwell plates $\left(3 \times 10^{5}\right.$ cells/well $)$, maintained overnight in Roswell Park Memorial Institute (RPMI)-1640 medium (Thermo Fisher Scientific) supplemented with $10 \%$ fetal calf serum (FCS) (Thermo Fisher Scientific) $\left(37^{\circ} \mathrm{C}, 5 \%\right.$ $\mathrm{CO}_{2}$ ) and reached $70 \%$ confluence the next day. They were made quiescent by overnight exposure to serum-free medium (SFM), then incubated with N-LDL, HOG-LDL $(10,25,50,100$ or $200 \mathrm{mg}$ protein/L) or 4-HNE (Cayman Chemical, Ann Arbor, Michigan, USA) (5-40 $\mu \mathrm{mol} / \mathrm{L})$ in PBS for up to 24 hours. In separate experiments to address effects of elevated glucose, cells were seeded into six-well plates $\left(1.5 \times 10^{5}\right.$ cells/well $)$ and maintained overnight in RPMI medium with $10 \%$ FCS. The next day, relevant concentrations of glucose or mannitol (osmotic control) were spiked into the media. HTR8/SVneo cells did not survive $5 \mathrm{mmol} / \mathrm{L} \mathrm{D}$-glucose possibly due to the rapid glucose consumption over 48 hours; therefore, $11 \mathrm{mmol} / \mathrm{L}$ D-glucose in its standard culture medium was designated as the glucose control. For high glucose conditions, cells were exposed to $30 \mathrm{mmol} / \mathrm{L}$ D-glucose (ie, $11 \mathrm{mmol} / \mathrm{L}$ D-glucose and $19 \mathrm{mmol} / \mathrm{L}$ additional D-glucose or mannitol). After 48 hours, cells were serumstarved (24 hours) with no change in glucose/mannitol concentrations, then exposed to N-LDL versus HOGLDL (50 mg LDL protein/L, 24 hours). Total treatment time in $11 \mathrm{mmol} / \mathrm{L}$ versus $30 \mathrm{mmol} / \mathrm{L}$ glucose was 96 hours. Each condition was studied in duplicate, and each experiment was performed in triplicate using different LDL preparations.

\section{Human trophoblast JAR cell culture}

Since cytotrophoblast HTR8/SVneo cells do not form a monolayer in Transwell plates, JAR cells (ATCC, Manassas, Virginia, USA) were used for this purpose. They were cultured for 12-14 days in RPMI-1640 medium with 10\% FCS (medium changed every 2 days) then for 24 hours in RPMI-1640 with 1\% FCS (JAR cells do not tolerate 
SFM). N-LDL or HOG-LDL (200 mg protein/L) were then added to the top of the semipermeable membrane (representing the apical side of the trophoblast) or the bottom (representing the basal side of the trophoblast) for up to 24 hours. Each condition was studied in duplicate with experiments in triplicate using different LDL preparations.

\section{Cell viability assay}

Cells were seeded into 96 -well plates $\left(2 \times 10^{4}\right.$ cells/well). After exposure to experimental conditions for 24 hours, cell viability was measured by CCK-8 (Dojindo Molecular Technologies) per manufacturer's instructions. Briefly, CCK-8 utilizes a water-soluble tetrazolium salt WST-8. On reduction by dehydrogenases in cells, a yellow coloured formazan product is formed, which is proportional to the number of living cells. The CCK-8 results were consistent with the trypan blue exclusion assay in our studies (data not shown).

Measurement of sFLT-1 and sENG in Culture Supernatants sFLT-1 and sENG in supernatants was measured by Quantikine ELISA assays (R\&D Systems, Minneapolis, Minnesota, USA) per manufacturer's instructions. The interassay coefficients of variation (CVs) were $10 \%$ and $16 \%$, respectively, and intra-assay CVs were $9 \%$ and $8 \%$, respectively. Data were presented as 'cell viability adjusted', that is, the biomarker of interest (ng/L)/ proportion of alive cells.

\section{Quantitative real-time PCR}

RNA extraction (RNeasy Mini Kit; Qiagen, Valencia, California, USA) was followed by cDNA synthesis (Superscript III, Invitrogen, Carlsbad, California, USA). Semiquantitative real-time PCR was performed for the sFLT-1 isoforms sFLT-1-I13 and sFLT-1-E15A, ENG (endoglin) and MMP-14. mRNA levels were normalised to ACTB (ß-actin). Relative quantitative values were obtained ( $\triangle \triangle \mathrm{Ct}$ method). Primer sequences included sFLT-1-I13 forward: ACAATCAGAGGTGAGCACTGCAA, sFLT-1-I13 reverse: TCCGAGCCTGAAAGTTAGCAA, sFLT-1-E15A forward: ACACAGTGGCCATCAGCAGTT, sFLT-1-E15A reverse: CCCGGCCATTTGTTATTGTTA; ENG forward: CAACAACCAAGGGCTGGGG, $E N G$ reverse: TGGAGATGGGACGGGTATGC; $M M P$-14 forward: CCTGCCTGCGTCCAT, $M M P-14$ reverse: TCCAGGGACGCCTCATCA and $A C T B$ forward: CAGTCGGTTGGAGCGAGCAT, ACTB reverse: GGATGGCAAGGGACTTCGTGTA.

\section{TEER measurements}

Transepithelial electrical resistance (TEER) was measured using an epithelial voltmeter with EndOhm chamber (EVOM system, WPI Instruments, Sarasota, Florida, USA), per manufacturer's instructions. The concentric electrodes were within the base of the chamber and the cap: a silver/silver chloride pellet in the centre plus an annular current electrode. An alternating current voltage (12.5 Hz square wave) was applied to the electrodes to avoid damage to both cells and electrodes. Cells were seeded on 12-well Transwell filters (12 mm diameter, 0.4 $\mu \mathrm{m}$ pore) (Thermo Fisher Scientific). The volume of media was $500 \mu \mathrm{L}$ inside the Transwell insert and $1.5 \mathrm{~mL}$ outside. TEER was measured at room temperature prior to media change (every 48 hours). TEER levels were measured over a period of 2-3 weeks, until a plateau was reached.

\section{Immunohistochemistry in human placentae}

Immunostaining of apolipoprotein B (ApoB), Ox-LDL and 4-HNE was performed in placental sections obtained at elective cesarean section beyond 32 weeks' gestation. Placental tissues were collected following a standardized protocol to avoid bias. ${ }^{20}$ Biopsies were taken from each quadrant of the placenta (four sample areas from each placenta). Images presented here were representative of two sample areas per patient (two fields per sample area). Written informed consent was obtained from all participants. Participants included women with pregestational type 1 diabetes $(n=3)$ and women without diabetes $(n=4)$. In those with diabetes, $\mathrm{HbA1c}$ values at the first trimester were $9.1 \%, 12.1 \%$ and $6.5 \%$, and at delivery were $6.8 \%$, $6.7 \%$ and $5.6 \%$, respectively. HbAlc was not routinely tested in women without diabetes. Maternal characteristics of the two groups are presented in online supplemental table 1 .

Formalin-fixed placental samples were dehydrated in a graded series of ethanol and embedded in paraffin. Serial sections $(8 \mu \mathrm{m})$ were cut, mounted on glass slides and deparaffinized using xylene and a graded series of ethanol (5 min for each step). Placental sections were incubated with primary goat anti-human ApoB (1:100), rabbit anti-human Ox-LDL $(1: 1000)$ and mouse anti4-HNE (1:100) (Abcam, Cambridge, Massachusetts, USA) $\left(4^{\circ} \mathrm{C}\right.$, overnight $)$, then incubated with secondary antibodies goat anti-rabbit (1:400), rabbit anti-goat (1:400), and goat anti-mouse, respectively (Vector Laboratories, Burlingame, California, USA) $\left(37^{\circ} \mathrm{C}, 1\right.$ hour $)$. Positive staining appeared brown after incubation with VECTASTAIN ABC reagent and DAB substrate. Sections were counterstained with hematoxylin. Control reactions omitting the primary antibodies did not reveal any staining. Sections were examined and images were captured using an Olympus microscope. Investigators were blinded to reduce bias in analyses.

\section{Statistical analysis}

Data are presented as means \pm SD. Experiments were conducted in duplicate or triplicate, with each replicated $\geq$ three times. Unpaired Student's t-test or one-way analysis of variance followed by post hoc Bonferroni test were used as appropriate (Prism 7 software; GraphPad Software, La Jolla, California, USA). A p value of $<0.05$ was considered significant. To denote statistical significance, asterisks were used for differences between HOGLDL and non-treated control and daggers for differences between N-LDL and HOG-LDL, unless stated otherwise. 

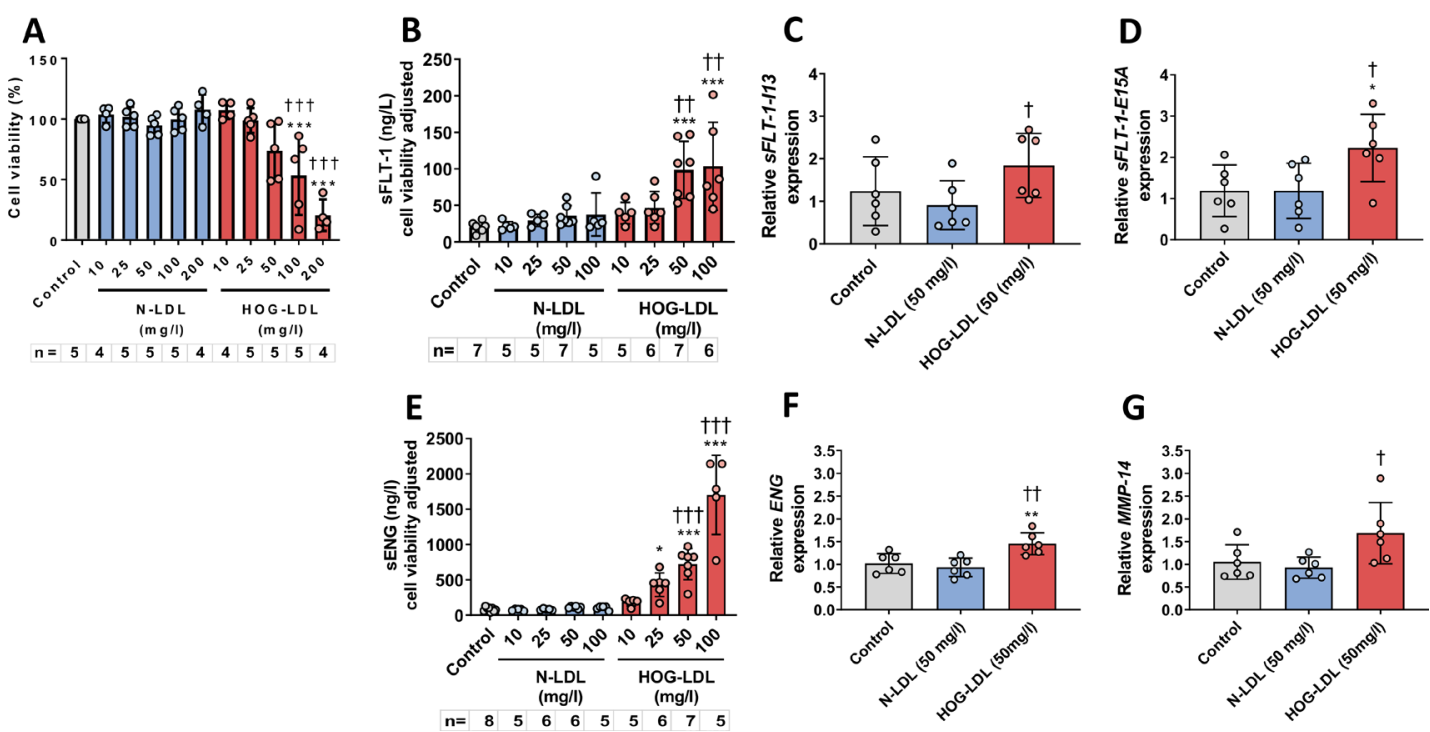

Figure 1 (A) Concentration-dependent changes of viability in HTR8/SVneo cells treated with N-LDL or HOG-LDL versus untreated control for 24 hours $\left({ }^{* * *} \mathrm{p}<0.001\right.$ vs untreated control; ${ }^{t+\dagger} \mathrm{p}<0.001 \mathrm{vs} \mathrm{N-LDL}$ at equivalent concentrations; one-way analysis of variance (ANOVA) with post hoc Bonferroni test). (B) HOG-LDL increased sFLT-1 release from semiconfluent HTR8/ SVneo cells at 24 hours $\left({ }^{* * \star} \mathrm{p}<0.001\right.$ vs untreated control; ${ }^{\dagger \dagger} p<0.01$ vs $\mathrm{N}$-LDL at equivalent concentrations; one-way ANOVA with post hoc Bonferroni test). (C) HOG-LDL (50 mg/L) increased $s F L T-1-113$ expression in HTR8/SVneo cells at 24 hours ( $p<0.05$ vs N-LDL; unpaired Student's t-test). (D) HOG-LDL (50 mg/L) increased sFLT-1-E15A expression in HTR8/SVneo cells at 24 hours ( ${ }^{*} p<0.05$ vs untreated control; ${ }^{\dagger} p<0.05$ vs N-LDL; unpaired Student's t-test). (E) HOG-LDL increased sENG release from semiconfluent HTR8/SVneo cells at 24 hours $\left({ }^{*} p<0.05,{ }^{* \star *} p<0.001\right.$ vs untreated control; ${ }^{+t \dagger} p<0.001$ vs $N-L D L$ at equivalent concentrations; one-way ANOVA with post hoc Bonferroni test). (F) HOG-LDL ( $50 \mathrm{mg} / \mathrm{L}$ ) increased membrane ENG expression in HTR8/SVneo cells at 24 hours $\left({ }^{* *} p<0.01\right.$ vs untreated control; ${ }^{+\dagger} p<0.01$ vs N-LDL; unpaired Student's t-test). (G) HOG-LDL ( $50 \mathrm{mg} / \mathrm{L}$ ) increased MMP-14 expression in HTR8/SVneo cells at 24 hours ( ${ }^{\dagger} \mathrm{p}<0.05$ vs N-LDL; unpaired Student's t-test). Data are presented as means \pm SD. HOG-LDL, heavily oxidized, glycated low-density lipoprotein; MMP-14, matrix metalloproteinase-14; N-LDL, native low-density lipoprotein; sENG, soluble endoglin; sFLT-1, soluble fms-like tyrosine kinase.

\section{RESULTS}

\section{HOG-LDL decreased HTR8/SVneo cell viability}

HOG-LDL (24 hours) decreased viability of HTR8/ SVneo cells in a concentration-dependent manner, but N-LDL had no effect (figure 1A). JAR cells were more resistant, with significant cytotoxicity only when HOGLDL concentration was $\geq 100 \mathrm{mg} / \mathrm{L}$ (online supplemental figure $1 \mathrm{~A})$.

\section{HOG-LDL induced SFLT-1 release and expression in HTR8/ SVneo}

As shown in figure 1B, sFLT-1 increased following 24 hours exposure to HOG-LDL (at 50 and $100 \mathrm{mg} / \mathrm{L}$ ); N-LDL had no effect. At $50 \mathrm{mg} / \mathrm{L}$ HOG-LDL versus N-LDL, sFLT-1 concentrations were $99 \pm 39 \mathrm{ng} / \mathrm{L}$ versus $36 \pm 14 \mathrm{ng} / \mathrm{L}(\mathrm{p}<0.001)$, respectively, while mRNA expression of sFLT-1-I13 was increased 2.0-fold $(\mathrm{n}=6, \mathrm{p}<0.05)$ and sFLT-1-E15A 1.9-fold $(\mathrm{n}=6, \mathrm{p}<0.05)$ (figure 1C,D). sFLT-1 protein release by JAR cells could not be detected, and sFLT-1-I13 and sFLT-1-E15A expression by JAR cells was low (data not shown).

\section{HOG-LDL induced release of sENG and enhanced expression of ENG in HTR8/SVneo}

As shown in figure 1E, sENG in HTR8/SVneo increased following 24 hours exposure to HOG-LDL versus N-LDL $(10-100 \mathrm{mg} / \mathrm{L})$ in a concentration-dependent manner. At $50 \mathrm{mg} / \mathrm{L}$ HOG- versus N-LDL, sENG concentrations were $725 \pm 222 \mathrm{ng} / \mathrm{L}$ versus $113 \pm 12 \mathrm{ng} / \mathrm{L}(\mathrm{p}<0.001)$, while mRNA expression of $E N G$ was increased 1.6-fold $(\mathrm{n}=6$, $\mathrm{p}<0.01)$ and $M M P-141.8$-fold $(\mathrm{n}=6, \mathrm{p}<0.05)$ (figure 1F,G) . In JAR cells, sENG release increased sixfold $(n=4, p<0.05)$ following 24 hours exposure to HOG-LDL $(50 \mathrm{mg} / \mathrm{mL})$ (online supplemental figure 1B), but expression of $E N G$ was low in these cells (data not shown), and expression of MMP-14 did not change after exposure to HOG-LDL versus $\mathrm{N}-\mathrm{LDL}(50 \mathrm{mg} / \mathrm{L}$ ) (online supplemental figure $1 \mathrm{C})$.

\section{4-HNE only partially replicated effects of HOG-LDL on HTR8/ SVneo}

HTR8/SVneo cells were exposed to 4-HNE (5-40 $\mu \mathrm{mol} / \mathrm{L}, 24$ hours). Effects on cell viability differed from that of HOG-LDL: overall, 4-HNE was less toxic than expected from work with other cell types ${ }^{1520}$; but at 40 $\mu \mathrm{mol} / \mathrm{L}$, viability decreased $(\mathrm{n}=4, \mathrm{p}<0.01)$ (figure $2 \mathrm{~A}$ ). sFLT-1 and sENG were measured in cell supernatant following 4-HNE exposure (5-40 $\mu \mathrm{mol} / \mathrm{L}, 24$ hours): sENG but not sFLT-1 was increased 2.7-fold $(\mathrm{n}=3, \mathrm{p}<0.05)$ (figure 2B,C).

\section{High glucose did not affect HTR8/SVneo viability or release of} antiangiogenic factors

As shown in figure 3A, neither high glucose (30 vs 11 mmol/L, 24-72 hours) nor mannitol affected HTR8/ SVneo viability. Likewise, neither high glucose nor 

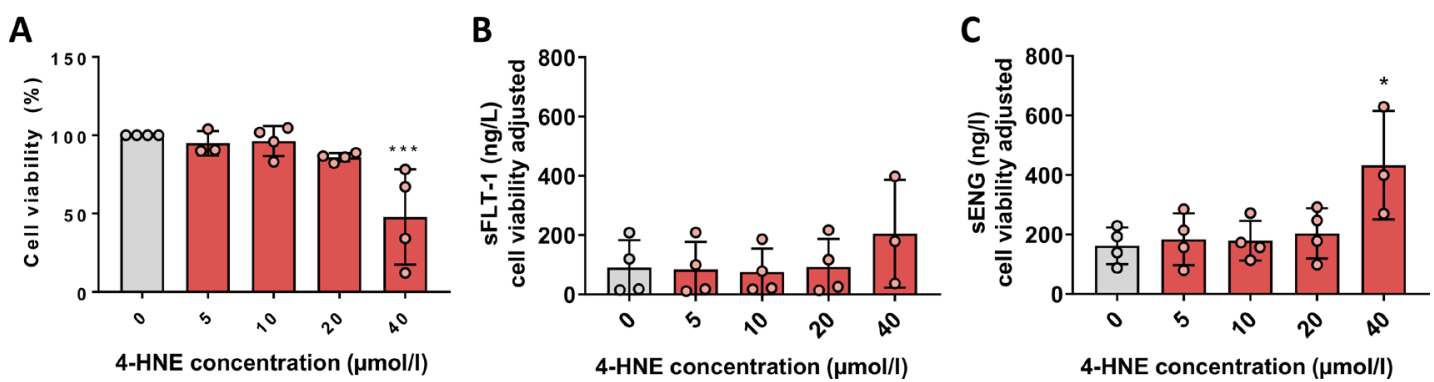

Figure 2 (A) 4-HNE at the highest concentration $\left(40 \mu \mathrm{mol} / \mathrm{L}, 24\right.$ hours) decreased HTR8/SVneo cell viability $\left({ }^{* \star *} \mathrm{p}<0.001\right.$ vs untreated control; one-way analysis of variance (ANOVA) with post hoc Bonferroni test). (B) sFLT-1 release from HTR8/SVneo cells was not significantly affected by exposure to 4-HNE (5-40 $\mu \mathrm{mol} / \mathrm{L}, 24$ hours). (C) sENG release from HTR8/SVneo cells was increased by exposure to $4-\mathrm{HNE}$ at the highest concentration ( $40 \mu \mathrm{mol} / \mathrm{L}, 24$ hours) $\left({ }^{*} \mathrm{p}<0.05\right.$ vs untreated control; one-way ANOVA with post hoc Bonferroni test). Data are presented as means \pm SD. 4-HNE, 4-hydroxynonenal; sENG, soluble endoglin; sFLT-1, soluble fms-like tyrosine kinase.

mannitol affected sFLT-1 or sENG concentrations in cell supernatants (figure 3B,C). Neither high glucose nor mannitol affected JAR viability or release of sENG in cell supernatants (online supplemental figure 2A,B).

\section{High glucose pretreatment enhanced the effects of HOG-LDL} on HTR8/Svneo viability and release of antiangiogenic factors High glucose pretreatment (30 vs $11 \mathrm{mmol} / \mathrm{L}, 72$ hours) enhanced the effect of $50 \mathrm{mg} / \mathrm{L}$ HOG-LDL on cell viability $(\mathrm{n}=3, \mathrm{p}<0.01)$ (figure $3 \mathrm{D})$. Compared with
N-LDL, HOG-LDL (50 mg/L) increased sFLT-1 and sENG release (figure $3 \mathrm{E}, \mathrm{F}$ ) and this was also amplified by pre-exposure to high glucose. Mannitol pretreatment did not affect HTR8/SVneo cell viability or release of antiangiogenic factors (data not shown). In contrast, JAR viability was similar following treatment with N-LDL and HOG-LDL (50 mg/L, 24 hours); however, high glucose pretreatment (30 vs $11 \mathrm{mmol} / \mathrm{L}, 72$ hours) decreased viability with both N-LDL and HOG-LDL treatment
A
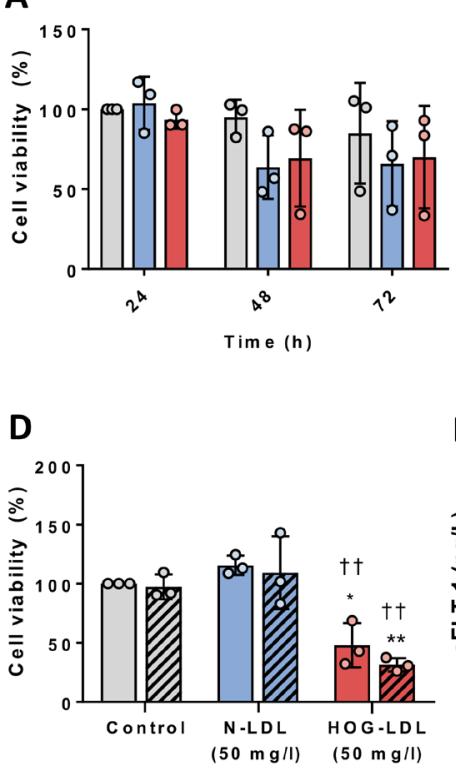

B

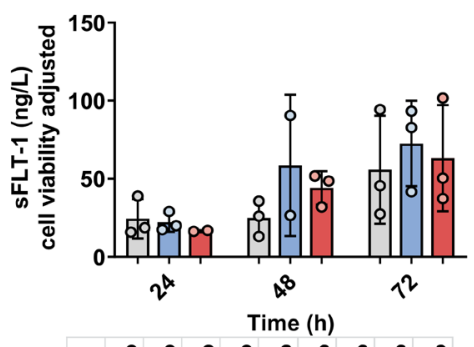

C

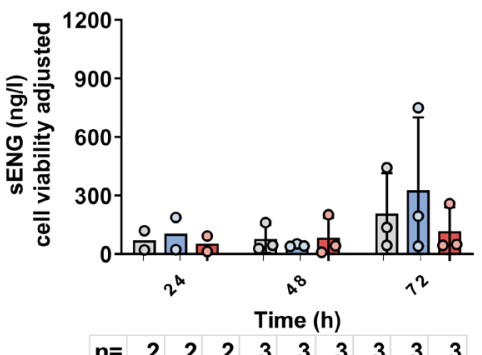

E

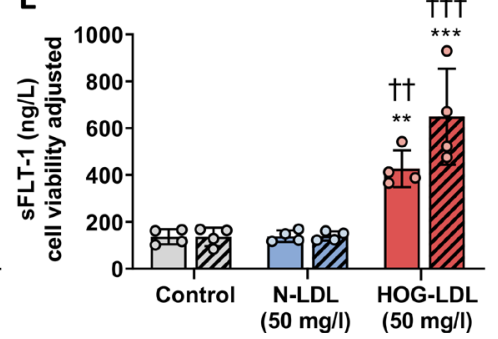

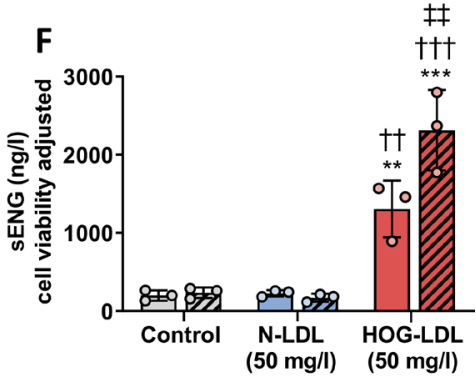

Figure 3 (A) Time-course (24-72 hours) viability of HTR8/SVneo cells exposed to $11 \mathrm{mmol} / \mathrm{L}$ D-glucose (glucose control), mannitol (osmotic control), versus $30 \mathrm{mmol} / \mathrm{L}$ D-glucose (high glucose). Release of (B) sFLT-1 and (C) sENG from HTR8/SVneo cells was not significantly affected by up to 72 hours exposure to high glucose (one-way analysis of variance (ANOVA) with post hoc Bonferroni test). Glucose control, grey bars; osmotic control, blue bars; high glucose, red bars. (D) HTR8/SVneo cell viability following pretreatment with high glucose, followed by N-LDL versus HOG-LDL exposure $\left({ }^{*} p<0.05\right.$, ${ }^{* *} p<0.01$ vs untreated control at equivalent glucose concentrations; ${ }^{\dagger \dagger} \mathrm{p}<0.01 \mathrm{vs} \mathrm{N-LDL}$ at equivalent glucose concentrations; one-way ANOVA with post hoc Bonferroni test). Release of (E) SFLT-1 and (F) sENG from HTR8/SVneo cells was increased following HOG-LDL exposure, and this effect was amplified by high glucose pretreatment $\left({ }^{* *} p<0.01,{ }^{* * *} p<0.001\right.$ vs untreated control

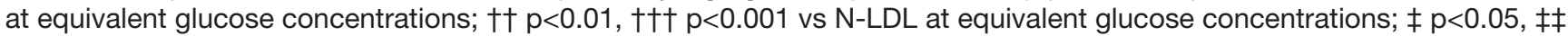
$\mathrm{p}<0.01$ vs HOG-LDL in control glucose conditions; one-way ANOVA with post hoc Bonferroni test). Glucose control, filled bars; high glucose, patterned bars. Untreated control, grey bars; N-LDL, blue bars; HOG-LDL, red bars. Data are presented as means \pm SD. HOG-LDL, heavily oxidized, glycated low-density lipoprotein; MMP-14, matrix metalloproteinase-14; N-LDL, native low-density lipoprotein; sENG, soluble endoglin; sFLT-1, soluble fms-like tyrosine kinase. 
A

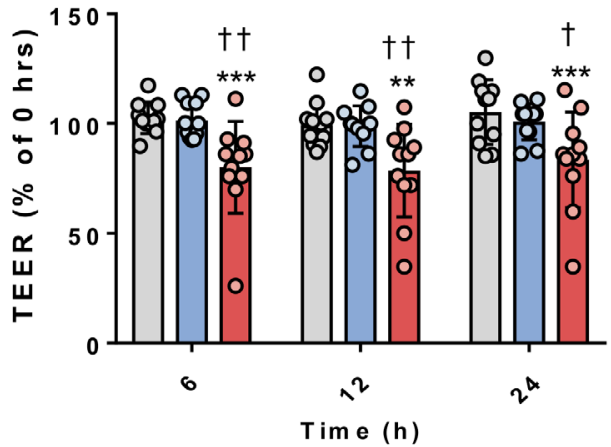

B

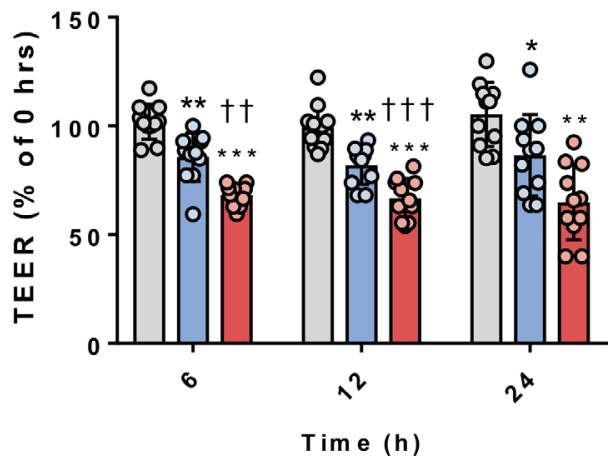

Figure 4 HOG-LDL decreased transepithelial electric resistance (TEER) in a trophoblast barrier model. JAR cells were cultured in Transwell plates for 12-14 days to form a monolayer, then treated with 1\% fetal calf serum for 18 hours. Cells were exposed to N-LDL versus HOG-LDL (200 mg/L) for up to 24 hours. (A) TEER decreased following 6, 12 and 24 hours exposure to HOG-LDL added to the top chamber (apical side of the trophoblast) $\left({ }^{\star *} p<0.01,{ }^{* * *} p<0.001\right.$ vs untreated control; ${ }^{\dagger} p<0.05$, ${ }^{+{ }^{+}} \mathrm{p}<0.01$ vs N-LDL at equivalent time points; one-way analysis of variance (ANOVA) with post hoc Bonferroni test), or (B) TEER decreased following 6, 12 and 24 hours exposure to N-LDL or HOG-LDL added to the bottom chamber (basal side of the trophoblast) $\left({ }^{*} \mathrm{p}<0.05,{ }^{* *} \mathrm{p}<0.01,{ }^{* \star} \mathrm{p}<0.001\right.$ vs untreated control; ${ }^{\dagger} \mathrm{p}<0.01,{ }^{\mathrm{t \dagger}} \mathrm{p}<0.001$ vs N-LDL at equivalent time point; oneway ANOVA with post hoc Bonferroni test). Data are presented as means \pm SD percentages relative to the $1 \%$ FCS control at 0 hour. Untreated control, grey bars; N-LDL, blue bars; HOG-LDL, red bars. HOG-LDL, heavily oxidized, glycated low-density lipoprotein; N-LDL, native LDL.

(online supplemental figure 3A) and the effect of HOGLDL on sENG was not amplified by high glucose (online supplemental figure 3B).

\section{HOG-LDL induced barrier breakdown in JAR cells}

HOG-LDL (200 $\mathrm{mg} / \mathrm{L})$ added to the top chamber (apical side of the JAR cell monolayer) caused a significant reduction of TEER at 6, 12 and 24 hours compared with N-LDL $(\mathrm{n}=11, \mathrm{p}<0.01, \mathrm{p}<0.01$ and $\mathrm{p}<0.05$, respectively) (figure $4 \mathrm{~A})$. HOG-LDL ( $200 \mathrm{mg} / \mathrm{L}$ ) added to the bottom chamber (basal side of the JAR cell monolayer) caused a significant reduction of TEER at 6 and 12 hours, but surprisingly not at 24 hours, compared with N-LDL $(\mathrm{n}=11, \mathrm{p}<0.01$ and $\mathrm{p}<0.001$, respectively) (figure $4 \mathrm{~B})$. Interestingly, N-LDL applied to the basal side also caused a reduction of TEER at all three time points $(\mathrm{p}<0.01$, $\mathrm{p}<0.01$ and $\mathrm{p}<0.05$, respectively) but not as severe as that induced by HOG-LDL.

\section{Detection of ApoB, Ox-LDL and 4-HNE in placentae from women with and without diabetes}

To determine whether extravasated LDL that has undergone oxidation is present in human placental tissue, we performed immunohistochemistry to detect ApoB, Ox-LDL and 4-HNE in a small number of placental sections from women with either pregestational type 1 diabetes $(n=3)$ or without diabetes $(n=4)$. ApoB, Ox-LDL and 4-HNE were present in all placentae, regardless of diabetes status. The staining for all three was predominantly located in the syncytiotrophoblast layer (figure 5).

\section{DISCUSSION}

Maternal diabetes greatly increases risk for PE. To investigate mechanisms, we developed an in vitro model by exposing cultured immortalized human placental trophoblasts to modified lipoproteins, similar to those present in vascular tissues of patients with diabetes, and/ or to high glucose. Our study is the first to demonstrate that in these cells modified LDL enhances release of two antiangiogenic factors sFLT-1 and sENG that are strongly implicated in $\mathrm{PE}$, and that it induces barrier dysfunction. N-LDL had no effect, and interestingly, 4-HNE, a major fatty acid oxidation product known to replicate the effects of HOG-LDL in other cell types, ${ }^{15}{ }^{21}$ had only modest effects. High glucose pretreatment amplified the effects of HOG-LDL, but by itself had no effect.

Supporting the relevance of these findings to PE, the concentrations of LDL used (10-200 mg/L) conservatively reflected those present in vivo. The highest concentration $(200 \mathrm{mg}$ protein/L) is equivalent to approximately $25 \%$ of plasma levels. Ox-LDL levels in atherosclerotic plaque are up to 70 -fold higher than those in plasma ${ }^{22}$ and extravasated Ox-LDL tends to aggregate, so that local concentrations at sites of barrier leakage may be much higher than tissue averages. Using histochemistry, we demonstrated the presence of modified LDL in a small number of placental tissues, but further evidence is needed to conclude whether higher amounts are present in women with diabetes compared with women without diabetes and to assess any relationship with PE status. It is important to note that the placental samples studied were collected, of necessity, at the time of delivery by cesarean section. All showed the presence of Ox-LDL, but the rate of accumulation during gestation remains unknown. Possibly, women with diabetes accumulate modified lipids in placental tissues earlier than women without diabetes, yet all may eventually reach the same 'saturation' point. Enhanced accumulation earlier in pregnancy could potentially drive antiangiogenic effects throughout gestation in women with diabetes. 

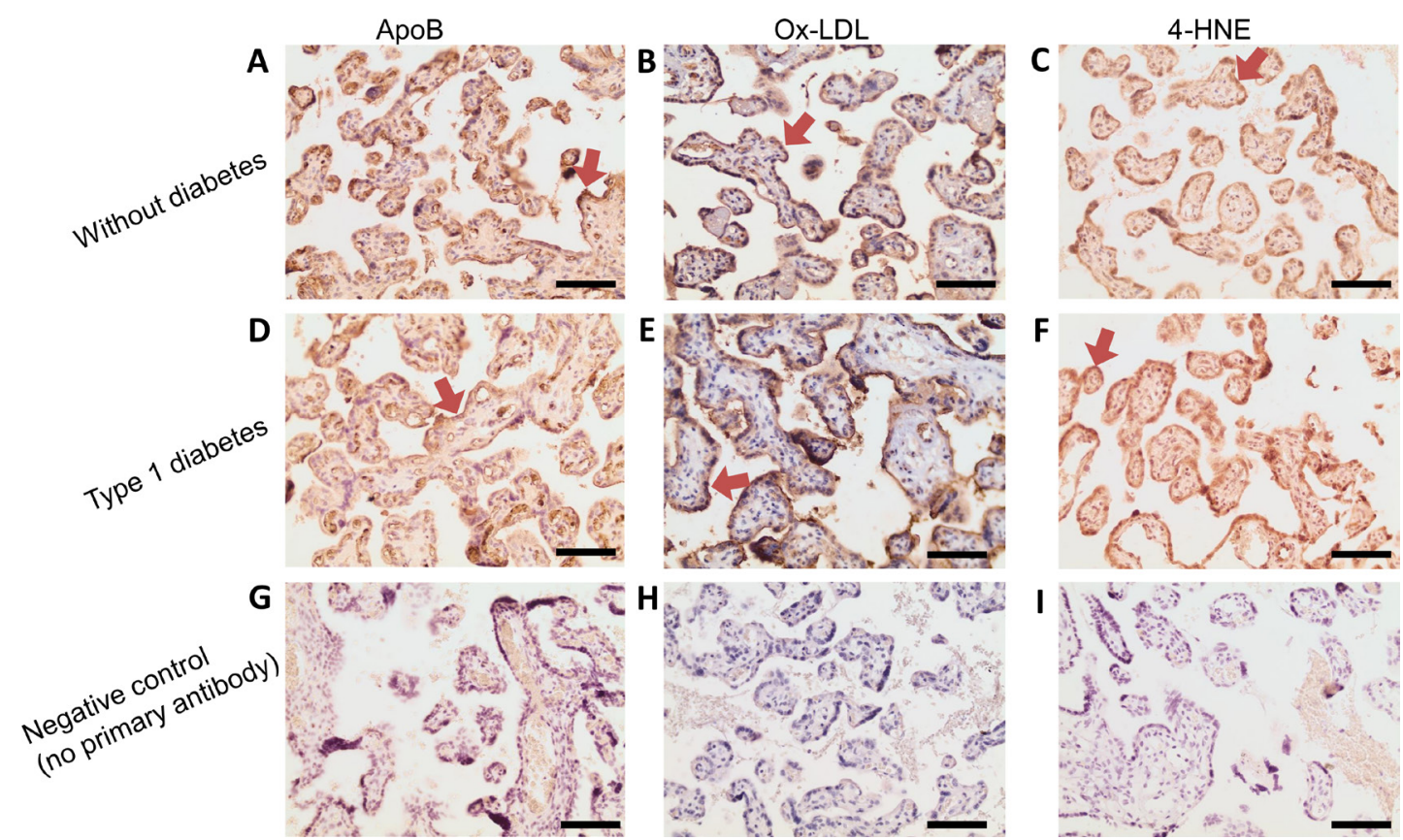

Figure 5 Presence of ApoB, Ox-LDL and 4-HNE in the human placenta. Representative placental images for (A) ApoB, (B) Ox-LDL and (C) 4-HNE in women without diabetes, and (D) ApoB, (E) Ox-LDL and (F) 4-HNE in women with type 1 diabetes. Positive staining was mainly in the syncytiotrophoblast layer (red arrows). Negative control for (G) ApoB, (H) Ox-LDL and (I) 4HNE omitting the primary antibodies. Images are representative of negative control staining for all sections. Magnification: $\times 20$. Scale bar=100 $\mu \mathrm{m}$. ApoB, apolipoprotein B; 4-HNE, 4-hydroxynonenal; Ox-LDL, oxidized low-density lipoprotein.

In the past, lipid abnormalities cross-sectionally associated with PE included high triglycerides, ${ }^{23}$ but prospectively, as reported in an earlier paper, we found no association with hypertriglyceridemia, but instead an association with first trimester $\mathrm{LDL}^{11}$ suggesting a parallel with atherogenesis. Evidence exists that plasma Ox-LDL is elevated in women with PE, but its source is unclear. $^{24} 25$

Limited studies have examined the presence of modified LDL in placental tissue. Such studies are challenging: it is important to control and standardize placental processing, to account for gestational age and to consider mode of delivery. An added problem concerns sample contamination by blood, since the placenta is highly vascular. Açıkgöz et $a l^{26}$ found that in PE, placental levels of Ox-LDL were lower than in healthy controls. This finding was against their (and our) hypothesis but their study may have been affected by some of the issues mentioned above.

In the current study, Ox-LDL was found in all human placentae analyzed, and our (at best semi-quantitative) initial findings show similar staining in placentae from women with and without diabetes. In agreement with our findings, Pecks et $a l^{27}$ reported Ox-LDL staining in trophoblast but to a lesser degree in villous stromal cells. The authors speculated that the process of oxidation resulted in accumulation of Ox-LDL particles at the apical placental surface, that is, the syncytiotrophoblast, reducing fetal cholesterol bioavailability. Importantly, results from term placentae may not be representative of what happens earlier in pregnancy, as discussed above. Pecks et $a l^{27}$ demonstrated increased accumulation of Ox-LDL within placentae of early-onset intrauterine growth restriction pregnancies compared with preterm control placentae. Basu et $a l^{28}$ conducted a study of placentae throughout normal gestation using tissues collected at termination and at term. They found that placental malondialdehyde concentrations were highest, and antioxidant defences lowest, early in gestation, concluding that placental oxidative stress declines as pregnancy advances. If so, the role of oxidized lipoproteins in pregnancies complicated by diabetes could be greatest early in gestation, that is, at times critical for successful placentation, when deficient angiogenesis may sow the seeds for later PE. These concepts have parallels in our own observations in women with type 1 diabetes: we observed associations of 'adverse' lipoprotein profiles early in gestation (first and second trimesters) with subsequent PE, but by the third trimester, these associations had disappeared. ${ }^{11}$

Few studies have examined the interaction of modified LDL with placental trophoblast cells. ${ }^{29}{ }^{30}$ Bonet et $a \hat{l}^{30}$ reported that $\mathrm{Ox}-\mathrm{LDL}$ is toxic to trophoblasts consistent with our findings regarding HOG-LDL. The mechanisms involved are unclear and likely complex, however, recent studies have found a direct cytotoxic effect of sFLT-1. ${ }^{31} 32$ This provides a potential mechanism for the toxicity of Ox-LDL not only towards trophoblast but in other tissues where Ox-LDL is implicated: in arteries and in the diabetic retina. ${ }^{12-16}$

When considering the role of Ox-LDL particles within the placenta, it is important to appreciate that 
these particles do not represent a unique entity. In the current study, we found that 4-HNE-derived adducts (lipoxidation products formed within Ox-LDL), previously shown to be toxic to other cell types, ${ }^{14}{ }^{153}$ had only modest effects on trophoblast cell viability and very little effect on the release of sFLT-1 and sENG. Previous studies provide evidence that treatment with oxysterols, a major group of components of modified LDL, increased ENG and sENG expression from trophoblast cells likely via increased expression of MMP-14. ${ }^{93435}$ In the current study, there was a modest increase in $M M P-14$ in response to HOG-LDL; this is consistent with the earlier finding that MMP-14 is the protease responsible for cleavage of ENG, increasing sENG release from trophoblast cells. Further work is needed to conclude if this is the case or if additional enzymes are also responsible.

Advanced glycation end products (AGEs) and lipoxidation end products (ALEs) are formed through free radical oxidation when proteins are exposed to reducing sugars and/or aldehyde-containing fatty acid fragments. In previous studies, exposure of HTR8/SVneo trophoblasts to AGEs/ALEs caused increased expression of sFLT-1. ${ }^{36}$ Plasma levels of AGE-ALE-modified LDL were elevated in patients with versus without diabetes, ${ }^{38}$ however, the role of AGEs in pregnancies complicated by diabetes and in the onset of PE is unclear. Li and Yang ${ }^{39}$ found that plasma AGEs in the second and third trimesters were significantly higher in women with gestational diabetes than those who were normoglycemic. In a crosssectional study, Chekir $e t a \hat{l}^{37}$ found that women with PE had significantly higher serum AGEs than healthy pregnant and non-pregnant controls, while AGE-modified proteins, the AGE receptor, RAGE, and 4-HNE were elevated in pre-eclamptic versus healthy placentae. In our previous work, we did not find any significant difference in serum levels of two AGE species ( $\mathrm{N}^{\varepsilon_{-}}$(carboxymethyl) lysine and hydroimidazolone) between the first and third trimester in women without diabetes versus women with type 1 diabetes, but decreased circulating soluble RAGE early in gestation (perhaps reflecting impaired ability to remove AGE products) was associated with later $\mathrm{PE}$ in type 1 diabetic women. ${ }^{4}$

Our initial results, although based on a small sample size, suggest that elevated glucose concentrations alone may not lead to an antiangiogenic response by trophoblasts, but co-existence of other factor(s), including the presence of modified lipoproteins whose formation is amplified by the presence of diabetes, may contribute. High glucose treatment (continuous or fluctuating) has previously been shown to increase $E N G$, sENG and sFLT-1 from trophoblast cell lines, ${ }^{40-42}$ however, in the present study, high glucose alone did not increase release of sFLT-1 or sENG from trophoblast cells.

There are limitations in our study. HTR8/SVneo and JAR cells responded differently to modified lipoprotein and high glucose exposure. While these immortalized cell lines maintain many of the morphological features of placental trophoblast, ${ }^{43}{ }^{44}$ they are unlikely to be completely representative of normal physiology. HTR8/ SVneo comprise two populations, trophoblast and stromal/mesenchymal cells, ${ }^{45}$ and whether our findings were complicated by the latter requires further investigation. The tumor origin of JAR cells ${ }^{46}$ may affect their proliferative responses. In addition, the glucose concentrations used in our culture experiments were, of necessity, higher than physiological levels. We report TEER measurements but recognise the need for additional evaluations of barrier structure and function. Preliminary fluorescein isothiocyanate (FITC-) dextran (10 kDa) permeability data suggested that leakage was unaffected by HOG-LDL, but electrical and leakage measures may reflect different properties of a cell monolayer, and other investigators have reported similar discrepancies. ${ }^{47} 48$ Future experiments should use a range of tracers with different molecular weights and Transwell membranes with different sized pores.

In summary, we present evidence that modified LDL may promote the development of $\mathrm{PE}$, particularly in the context of maternal diabetes, through two distinct effects on trophoblasts: it enhances the release of antiangiogenic factors, and it impairs barrier function. Further studies are needed to investigate how trophoblasts release antiangiogenic factors in response to HOGLDL and to elucidate whether and how modified LDL impairs placental barrier function. We also demonstrate that modified LDL is present in human placental villi at term, and even though, by semiquantitative measures, we found no difference in villous staining patterns of ApoB, Ox-LDL and 4-HNE in women with versus without diabetes, we show that elevated glucose levels amplify the effects of modified LDL. Future studies with a larger number of placentae with higher power images are needed. Improved understanding of the role of modified lipoproteins in promoting PE in diabetes may lead to new strategies to treat and prevent this common complication of pregnancy.

Acknowledgements We are grateful to $\mathrm{E}$ Chang and $\mathrm{M}$ Sterrett and the nursing staff (Obstetrics and Gynecology, Medical University of South Carolina) and the patients who participated in this study. The skilled and dedicated assistance of the following individuals is acknowledged: M Leyva, R Chow, C B Kelly (Division of Endocrinology, Medical University of South Carolina); K H Lee, A Kourtidis (Department of Regenerative Medicine, Medical University of South Carolina)

Contributors All authors made significant contributions to the study concept, design and acquisition of the data. RHMcL performed the experiments and RHMcL and TJL undertook the statistical analysis of the data. RHMcL and TJL drafted the manuscript, and all authors contributed critically to its revision. All authors approved the final version of the manuscript. RHMcL and TJL are the guarantors of this work.

Funding DPB is funded by UKRI NC3Rs, MRC and Invest Northern Ireland.

Competing interests None declared.

Patient consent for publication Not required.

Ethics approval The study was approved by the Institutional Review Board (IRB Number: Pro00070368) at Medical University of South Carolina and was conducted according to Declaration of Helsinki principles. 
Provenance and peer review Not commissioned; externally peer reviewed.

Data availability statement Data are available upon reasonable request. The data that support the findings of this study are available from the corresponding author upon reasonable request.

Supplemental material This content has been supplied by the author(s). It has not been vetted by BMJ Publishing Group Limited (BMJ) and may not have been peer-reviewed. Any opinions or recommendations discussed are solely those of the author(s) and are not endorsed by BMJ. BMJ disclaims all liability and responsibility arising from any reliance placed on the content. Where the content includes any translated material, BMJ does not warrant the accuracy and reliability of the translations (including but not limited to local regulations, clinical guidelines, terminology, drug names and drug dosages), and is not responsible for any error and/or omissions arising from translation and adaptation or otherwise.

Open access This is an open access article distributed in accordance with the Creative Commons Attribution 4.0 Unported (CC BY 4.0) license, which permits others to copy, redistribute, remix, transform and build upon this work for any purpose, provided the original work is properly cited, a link to the licence is given, and indication of whether changes were made. See: https://creativecommons.org/ licenses/by/4.0/.

ORCID IDs

Rebecca Helen McLeese http://orcid.org/0000-0003-0647-2503

Timothy J Lyons http://orcid.org/0000-0003-2106-1622

\section{REFERENCES}

1 Hanson U, Persson B. Outcome of pregnancies complicated by type 1 insulin-dependent diabetes in Sweden: acute pregnancy complications, neonatal mortality and morbidity. Am J Perinatol 1993;10:330-3.

2 Levine RJ, Maynard SE, Qian C, et al. Circulating angiogenic factors and the risk of preeclampsia. N Engl J Med 2004;350:672-83.

3 Levine RJ, Lam C, Qian C, et al. Soluble endoglin and other circulating antiangiogenic factors in preeclampsia. N Engl J Med 2006;355:992-1005.

4 Yu Y, Jenkins AJ, Nankervis AJ, et al. Anti-Angiogenic factors and pre-eclampsia in type 1 diabetic women. Diabetologia 2009;52:160-8.

5 Kendall RL, Thomas KA. Inhibition of vascular endothelial cell growth factor activity by an endogenously encoded soluble receptor. Proc Natl Acad Sci U S A 1993;90:10705-9.

6 Heydarian M, McCaffrey T, Florea L, et al. Novel splice variants of sFlt1 are upregulated in preeclampsia. Placenta 2009;30:250-5.

7 Souders CA, Maynard SE, Yan J, et al. Circulating levels of sFlt1 splice variants as predictive markers for the development of preeclampsia. Int J Mol Sci 2015;16:12436-53.

8 Kaitu'u-Lino Tu'uhevaha J, Palmer KR, Whitehead CL, et al. Mmp-14 is expressed in preeclamptic placentas and mediates release of soluble endoglin. Am J Pathol 2012;180:888-94.

9 Valbuena-Diez AC, Blanco FJ, Oujo B, et al. Oxysterol-Induced soluble endoglin release and its involvement in hypertension. Circulation 2012;126:2612-24.

10 Cavero-Redondo I, Martínez-Vizcaíno V, Soriano-Cano A, et al. Glycated haemoglobin A1c as a predictor of preeclampsia in type 1 diabetic pregnant women: a systematic review and meta-analysis. Pregnancy Hypertens 2018;14:49-54.

11 Basu A, Alaupovic P, Wu M, et al. Plasma lipoproteins and preeclampsia in women with type 1 diabetes: a prospective study. $J$ Clin Endocrinol Metab 2012;97:1752-62.

12 Wu M, Chen Y, Wilson K, et al. Intraretinal leakage and oxidation of LDL in diabetic retinopathy. Invest Ophthalmol Vis Sci 2008:49:2679-85.

13 Diffley JM, Wu M, Sohn M, et al. Apoptosis induction by oxidized glycated LDL in human retinal capillary pericytes is independent of activation of MAPK signaling pathways. Mol Vis 2009;15:135-45.

14 Du M, Wu M, Fu D, et al. Effects of modified LDL and HDL on retinal pigment epithelial cells: a role in diabetic retinopathy? Diabetologia 2013;56:2318-28.

15 Fu D, Yu JY, Connell AR, et al. Beneficial effects of berberine on oxidized LDL-induced cytotoxicity to human retinal Müller cells. Invest Ophthalmol Vis Sci 2016;57:3369-79.

16 Song W, Barth JL, Yu Y, et al. Effects of oxidized and glycated LDL on gene expression in human retinal capillary pericytes. Invest Ophthalmol Vis Sci 2005;46:2974-82.

17 Shi Y, Qian J, Zhang F, et al. Low molecular weight heparin (nadroparin) improves placental permeability in rats with gestational diabetes mellitus via reduction of tight junction factors. Mol Med Rep 2020;21:623-30.

18 Cvitic S, Novakovic B, Gordon L, et al. Human fetoplacental arterial and venous endothelial cells are differentially programmed by gestational diabetes mellitus, resulting in cell-specific barrier function changes. Diabetologia 2018;61:2398-411.

19 Leach L, Taylor A, Sciota F. Vascular dysfunction in the diabetic placenta: causes and consequences. J Anat 2009;215:69-76.

20 Burton GJ, Sebire NJ, Myatt L, et al. Optimising sample collection for placental research. Placenta 2014;35:9-22.

21 Wu M, Yang S, Elliott MH, et al. Oxidative and endoplasmic reticulum stresses mediate apoptosis induced by modified LDL in human retinal Müller cells. Invest Ophthalmol Vis Sci 2012;53:4595-604.

22 Nishi K, Itabe $\mathrm{H}$, Uno M, et al. Oxidized LDL in carotid plaques and plasma associates with plaque instability. Arterioscler Thromb Vasc Biol 2002;22:1649-54.

23 Vrijkotte TGM, Krukziener N, Hutten BA, et al. Maternal lipid profile during early pregnancy and pregnancy complications and outcomes: the ABCD study. J Clin Endocrinol Metab 2012;97:3917-25.

24 Uzun H, Benian A, Madazli R, et al. Circulating oxidized low-density lipoprotein and paraoxonase activity in preeclampsia. Gynecol Obstet Invest 2005;60:195-200.

25 Qiu C, Phung TTT, Vadachkoria S, et al. Oxidized low-density lipoprotein (Oxidized LDL) and the risk of preeclampsia. Physiol Res 2006;55:491-500.

26 Açıkgöz S, Bayar UO, Can M, et al. Levels of oxidized LDL, estrogens, and progesterone in placenta tissues and serum paraoxonase activity in preeclampsia. Mediators Inflamm 2013;2013:1-6

27 Pecks U, Rath W, Caspers R, et al. Oxidatively modified LDL particles in the human placenta in early and late onset intrauterine growth restriction. Placenta 2013;34:1142-9.

28 Basu J, Bendek B, Agamasu E, et al. Placental oxidative status throughout normal gestation in women with uncomplicated pregnancies. Obstet Gynecol Int 2015;2015:1-6.

29 Bonet B, Chait A, Gown AM, et al. Metabolism of modified LDL by cultured human placental cells. Atherosclerosis 1995;112:125-36.

30 Bonet B, Hauge-Gillenwater H, Zhu XD, et al. LDL oxidation and human placental trophoblast and macrophage cytotoxicity. Proc Soc Exp Biol Med 1998;217:203-11.

31 Miyake T, Kumasawa K, Sato N, et al. Soluble VEGF receptor 1 (sFLT1) induces non-apoptotic death in ovarian and colorectal cancer cells. Sci Rep 2016;6:24853.

32 Yamashita M, Kumasawa K, Miyake T, et al. Soluble Flt-1 Has Cytotoxic Effects on BeWo choriocarcinoma cells. Reprod Sci 2018;25:830-6.

33 Fu D, Wu M, Zhang J, et al. Mechanisms of modified LDL-induced pericyte loss and retinal injury in diabetic retinopathy. Diabetologia 2012;55:3128-40.

34 Brownfoot FC, Hannan N, Onda K, et al. Soluble endoglin production is upregulated by oxysterols but not quenched by pravastatin in primary placental and endothelial cells. Placenta 2014;35:724-31.

35 Henry-Berger J, Mouzat K, Baron S, et al. Endoglin (CD105) expression is regulated by the liver $X$ receptor alpha $(\mathrm{NR} 1 \mathrm{H} 3)$ in human trophoblast cell line JAR. Biol Reprod 2008;78:968-75.

36 Huang QT, Zhang M, Zhong M, et al. Advanced glycation end products as an upstream molecule triggers ROS-induced SFIt-1 production in extravillous trophoblasts: a novel bridge between oxidative stress and preeclampsia. Placenta 2013;34:1177-82.

37 Chekir C, Nakatsuka M, Noguchi S, et al. Accumulation of advanced glycation end products in women with preeclampsia: possible involvement of placental oxidative and nitrative stress. Placenta 2006;27:225-33.

38 Brownlee M, Cerami A, Vlassara H. Advanced glycosylation end products in tissue and the biochemical basis of diabetic complications. N Engl J Med 1988;318:1315-21.

$39 \mathrm{Li} \mathrm{S}$, Yang $\mathrm{H}$. Relationship between advanced glycation end products and gestational diabetes mellitus. J Matern Fetal Neonatal Med 2019:32:2783-2789.

40 La Sala L, Pujadas G, De Nigris V, et al. Oscillating glucose and constant high glucose induce endoglin expression in endothelial cells: the role of oxidative stress. Acta Diabetol 2015;52:505-12.

41 Han CS, Herrin MA, Pitruzzello MC, et al. Glucose and metformin modulate human first trimester trophoblast function: a model and potential therapy for diabetes-associated uteroplacental insufficiency. Am J Reprod Immunol 2015;73:362-71.

42 Cawyer C, Afroze SH, Drever N, et al. Attenuation of hyperglycemiainduced apoptotic signaling and anti-angiogenic milieu in cultured cytotrophoblast cells. Hypertens Pregnancy 2016;35:159-69. 
43 Orendi K, Kivity V, Sammar M, et al. Placental and trophoblastic in vitro models to study preventive and therapeutic agents for preeclampsia. Placenta 2011;32 Suppl:S49-54.

44 Sullivan MHF. Endocrine cell lines from the placenta. $\mathrm{Mol} \mathrm{Ce} / \mathrm{l}$ Endocrinol 2004;228:103-19.

45 Abou-Kheir W, Barrak J, Hadadeh O, et al. HTR-8/SVneo cell line contains a mixed population of cells. Placenta 2017:50:1-7.

46 Pattillo RA, Gey GO. The establishment of a cell line of human hormone-synthesizing trophoblastic cells in vitro. Cancer Res 1968;28:1231-6.
47 Bischoff I, Hornburger MC, Mayer BA, et al. Pitfalls in assessing microvascular endothelial barrier function: impedance-based devices versus the classic macromolecular tracer assay. Sci Rep 2016;6:23671.

48 Knyazev EN, Petrov VA, Gazizov IN, et al. Oxyquinoline-Dependent changes in Claudin-Encoding genes contribute to impairment of the barrier function of the trophoblast monolayer. Bull Exp Biol Med 2019;166:369-72. 